\title{
BMJ Open Maternal trauma due to motor vehicle crashes and pregnancy outcomes: a systematic review and meta-analysis
}

Carmen Amezcua-Prieto (D) ,1,2,3 Jennifer Ross, ${ }^{4}$ Ewelina Rogozińska, ${ }^{5,6}$ Patritia Mighiu, ${ }^{5}$ Virginia Martínez-Ruiz, ${ }^{1,2,3}$ Karim Brohi, ${ }^{4}$ Aurora Bueno-Cavanillas, ${ }^{1,2,3}$ Khalid Saeed Khan, ${ }^{1,2,5}$ Shakila Thangaratinam ${ }^{5}$

To cite: Amezcua-Prieto C, Ross J, Rogozińska E, et al. Maternal trauma due to motor vehicle crashes and pregnancy outcomes: a systematic review and meta-analysis. BMJ Open 2020;10:e035562. doi:10.1136/ bmjopen-2019-035562

- Prepublication history and additional material for this paper are available online. To view these files, please visit the journal online (http://dx.doi org/10.1136/bmjopen-2019035562).

Received 05 November 2019 Revised 09 July 2020 Accepted 04 August 2020
Check for updates

(C) Author(s) (or their employer(s)) 2020. Re-use permitted under CC BY-NC. No commercial re-use. See rights and permissions. Published by BMJ.

For numbered affiliations see end of article.

Correspondence to Dr Aurora Bueno-Cavanillas; abueno@ugr.es

\section{ABSTRACT}

Objectives To systematically review and quantify the effect of motor vehicle crashes (MVCs) in pregnancy on maternal and offspring outcomes.

Design Systematic review and meta-analysis of observational data searched from inception until 1 July 2018. Searching was from June to August 2018 in Medline, Embase, Web of Science, Scopus, Latin-American and Caribbean System on Health Sciences Information, Scientific Electronic Library Online, TRANSPORT, International Road Research Documentation, European Conference of Ministers of Transportation Databases, Cochrane Database of Systematic Reviews and Cochrane Central Register.

Participants Studies were selected if they focused on the effects of exposure MVC during pregnancy versus non-exposure, with follow-up to verify outcomes in various settings, including secondary care, collision and emergency, and inpatient care.

Data synthesis For incidence data, we calculated a pooled estimate per 1000 women. For comparison of outcomes between women involved and those not involved in MVC, we calculated ORs with $95 \%$ Cls. Where possible, we statistically pooled the data using the random-effects model. The quality of studies used in the comparative analysis was assessed with NewcastleOttawa Scale.

Results We included 19 studies (3222066 women) of which the majority was carried out in high-income countries (18/19). In population-level studies of women involved in MVC, maternal death occurred in 3.6 per 1000 (95\% Cl 0.25-10.42; 3 studies, 12000 women; Tau=1.77), and fetal death or stillbirth in 6.6 per $1000(95 \% \mathrm{Cl}$ 3.81-10.12; 8 studies, 47992 women; $\mathrm{I}^{2}=92.6 \%$ ). Pooled incidence of complications per 1000 women involved in MVC was labour induction (276.43), preterm delivery (191.90) and caesarean section (166.65). Compared with women not involved in MVC, those involved had increased odds of placental abruption (OR 1.43, 95\% Cl 1.27-1.63; 3 studies, 1500825 women) and maternal death (OR 202.27; 95\% Cl 110.60-369.95; 1 study, 1094559 women).

Conclusion Pregnant women involved in MVC were at higher risk of maternal death and complications than those not involved.

PROSPERO registration number CRD42018100788.

\section{Strengths and limitations of this study}

- This is the first systematic review examining the link between involvement in motor vehicle crashes (MVCs), mortality and adverse outcomes that includes evaluation of study quality assessment.

- This is the second systematic review looking at outcomes following MVC in pregnancy.

- We conducted our review using a prospectively registered protocol and reported it in accordance with the international standards.

- Outcomes variables correspond to any trimester, not to specific trimesters.

Outcomes according to seat belt use are scarce, since only two studies use population-level data.

\section{INTRODUCTION}

Up to half of all women in developed countries drive motor vehicles ${ }^{1}$ and the consequences of road traffic-related injuries involving pregnant women can be severe. ${ }^{2}$ Indeed, motor vehicle crashes (MVCs) are the most common cause of non-obstetric trauma associated with fetal deaths (2.3 per 100000 live births). ${ }^{3}$ The risk of adverse outcomes resulting from an MVC increases in the second trimester of pregnancy if the pregnant women were the driver ${ }^{4}$; however, this does not appear to be the case for pregnant passengers or pedestrians. ${ }^{5}$ A maternal mortality rate of 3.5 women per 100000 is reported following MVCs in pregnant women. ${ }^{6}$ Mechanisms of injury recorded within the pregnant population of the UK national trauma registry, the Trauma Audit and Research Network, saw an increased rate of vehicular collision in pregnant women when compared with the non-pregnant cohort. ${ }^{7}$ In 2001-2008, 2.9\% of pregnant women in North Carolina were drivers in one or more crashes. ${ }^{8}$ In the USA, data from the National Automotive Sampling System/Crashworthiness Data System reflect that when vehicles with pregnant women are 
involved in collision, $50 \%$ of those women will sustain an injury. ${ }^{9}$ There are few safety guidelines on travelling by car during pregnancy. ${ }^{10-12}$ The focus of these tends to be on questions around the use of seat belts and the activation of airbags in the car. ${ }^{12}$

There is a reported association between MVC and maternal mortality. ${ }^{13}$ Moreover, further associations such as the trigger for immediate delivery or being more likely to die are reported with severe blunt injury (Injury Severity Score (ISS) of 9 or above, or systolic blood pressure $<90 \mathrm{~mm} \mathrm{Hg}$ on arrival). ${ }^{14}$ Involvement in MVC is also associated with perinatal mortality, ${ }^{15}$ injuries to the abdominal region, ${ }^{16}$ placental abruption secondary to increased intra-abdominal pressure, ${ }^{17}$ preterm birth and caesarean section. ${ }^{6}$ However, more data are required in relation to areas such as fetal outcomes and higher risk pregnancies, particularly regarding sociodemographic characteristics of the mother, specific trimester of pregnancy when exposed to trauma, socioeconomic country conditions, severity and type of trauma, and collision characteristics such as speed. A systematic review on trauma in pregnancy (including five studies reporting complications of involvement in MVC, and fourteen other studies on other forms of trauma) showed that MVC and domestic violence were the most common causes of traumatic injury during pregnancy. ${ }^{4}$ No quality assessment of the included studies was reported in this review. Previous non-systematic reviews have published strategies used to monitor women and fetuses after a crash. ${ }^{18-21}$ However, to our knowledge there is no systematic review or metaanalysis focused on the maternal and fetal outcomes after MVC in pregnancy.

\section{Review objectives}

As the clinical impact on the mother and fetus after MVC has not been well documented, we conducted a systematic review of the effect on maternal and fetal outcomes of MVC in pregnant women, compared with those not involved in a collision.

\section{METHODS}

We conducted a systematic review and reported it according to recommended standards. ${ }^{22}$

\section{Literature search}

Searching was from June to August 2018. The following databases were used to identify relevant literature: Medline, Embase, Web of Science, Scopus, LatinAmerican and Caribbean System on Health Sciences Information, Science Citation Index, Scientific Electronic Library Online, TRANSPORT, International Road Research Documentation, European Conference of Ministers of Transportation Databases, Cochrane Database of Systematic Reviews and Cochrane Central Register of Controlled Trials. We also sought to identify unpublished research or research reported in the grey literature by searching a range of relevant databases, including the
Inside Conferences, Systems for Information on Grey Literature and Dissertation Abstracts. Furthermore, the searches of the medical database were supplemented with the internet search using a general search engine (eg, Google, www.google.co.uk/) and safetylit.org. Language and date restrictions were not applied to electronic searches. Relevant studies were identified using a combination of, but not limited to, the medical subject headings and keywords for "motor vehicle collision" (OR road traffic collision OR crash OR collision) and "pregnancy" (OR pregnant women OR gravid women OR childbearing women OR maternal).

\section{Review inclusion criteria}

Papers were selected if they studied the effects of exposure to trauma due to involvement in an MVC during pregnancy versus non-exposure, with follow-up to verify outcomes in various settings including secondary care, collision and emergency, and inpatient care. Observational studies (cohort studies, case-control design, nonintervention arms of randomised controlled trials) were included. Case series and case reports were excluded. Online supplemental appendix 1 shows the search strategy for Medline (via Ovid) and online supplemental appendix 2 the excluded studies with reasons.

\section{Data extraction and study quality assessment}

A double screening of papers was carried out. Two reviewers (CA-P and JR) independently extracted the relevant data from each full-text article and data were recorded using a standardised data extraction form. A data extraction form was piloted for each study design and amended as required. Discrepancies were resolved by consensus or by a discussion with a third senior author (ER). We extracted data on (a) severe adverse maternal outcomes such as maternal death, miscarriage and preterm birth $(<37 / 40$ and $<34 / 40)$; (b) severe adverse fetal outcomes such as intrauterine death/stillbirth and neonatal death. Secondary outcomes were: (a) individual components of maternal outcomes such as preterm labour, mode of delivery (vaginal delivery vs caesarean section), premature rupture of membranes (PROM), preterm PROM, placental abruption, chorioamnionitis/ sepsis and maternal admission to an intensive care unit (ICU) or high dependency unit; (b) individual components of fetal outcomes: respiratory distress syndrome, neonatal ICU admission, low birth weight and small for gestational age.

We also extracted data on (1) adverse outcomes in pregnant women involved in MVC and their offspring in subgroups according to maternal characteristics (low, high and any risk), trimester of exposure, country (low and middle income, high income), type of trauma (penetrating, blunt, burns), severity of trauma (mild, moderate, severe), seat belt use (yes, no), study quality (low, high); (2) risk factors for pregnancy complications following MVC such as maternal characteristics (age, parity, high risk pregnancy, gestational age), type of trauma, type of 
motor vehicle, type of collision, collision characteristic (stationary, high or moderate speed) and seat belt use.

The quality assessment of studies was independently evaluated by two reviewers (JR and CA-P) using the Newcastle-Ottawa Scale. ${ }^{23}$ This scale includes 8 items, 4 items about selection criteria of cases or cohorts in casecontrol or cohort designs, respectively; 2 items about comparability between groups (in both designs); and 3 items about exposure criteria in case-control designs and about outcomes in cohort designs. Any of those studies could be awarded a maximum of one star for each numbered item within the selection and exposure categories. A maximum of two stars could be given for comparability. For the incidence analysis, we considered six aspects ${ }^{24}$ : (1) representativeness of cohort; (2) design; (3) method of sampling; (4) adequacy of follow-up; (5) if the outcomes were adequately ascertained and (6) if measurement or misclassification bias was minimised. Studies without these features or with unclear reporting were classified to have a high risk of bias.

\section{Patient and public involvement}

No patient involved.

\section{Data synthesis}

We undertook random-effects meta-analysis to determine the ORs with 95\% CIs for maternal and offspring complications from MVC. We estimated heterogeneity between the included studies with $\mathrm{X}^{2}$ test of $\mathrm{Q}\left(\mathrm{I}^{2}\right)$ excepting when not enough studies were in the meta-analysis, ${ }^{2}{ }^{3}$ and we pooled the rates of maternal/fetal complications and reported with $95 \%$ CI. For each primary outcome, a meta-analysis was conducted for studies sufficiently homogeneous in terms of the characteristics of participants and exposure. The subgroup analysis was applied in: (a) trimester of pregnancy during which the trauma occurred; (b) maternal risk status (low, high, any risk); (c) type of trauma; (d) severity of trauma (using the ISS to categorise the severity of trauma sustained following $\mathrm{MVC}^{25}$; (e) setting (low/middle-income, high-income country); (f) year of study publication: (before or after the introduction of mandatory seat belt legislature in the country of study); and (g) study quality according to the Newcastle and Ottawa Scale. ${ }^{23}$

\section{RESULTS}

\section{Study selection}

Out of 1739 retrieved references, 19 studies met the eligibility criteria (figure 1). Five of these reported data allow us to compare pregnancy complications between pregnant women involved in MVC and those not involved in MVC. ${ }^{6 ~}{ }^{26-28}$ The totality of the studies $(n=19)$ contributed to the analysis of the incidence of pregnancy complications among women involved in MVC. ${ }^{6}$ 17 26-40

\section{Characteristics of included studies}

The characteristics of included studies are in table 1 . Included studies were published between 1993 and 2016. Most of them were carried out in developed, high-income countries such as the USA $(14 / 18),{ }^{8} 26$ 28-30 32-39 Sweden $(1 / 19),{ }^{27}$ Kuwait $(1 / 19)^{17}$ and Israel $(1 / 19){ }^{40}$ The number of included pregnant women varies, ranging from 39 to 1094559 . The data were sourced from hospital records/trauma registries $(7 / 19)^{17303134373840}$ or from population-level databases (12/19). ${ }^{26826-29} 3233353639$ The majority of studies collected information on outcomes of pregnant women involved in MVC during any trimester of pregnancy. Eight out of 19 studies reported information about the use of safety devices such as seat belts and/ or airbags. ${ }^{26} 293234$ 36-38 Also in eight studies, the authors assessed the severity of MVC injuries with five of these using a validated tool ${ }^{2830343740}$-most of them reporting ISS $^{28303440}$ and one the Revised Trauma Scale. ${ }^{37}$

\section{Quality assessment}

Sixty per cent of studies had a low risk of bias with regards to the adequacy of representativeness and random sample selection $(12 / 19)$. None of the studies was prospective. The categories of follow-up of more than $80 \%$ of participants, outcome ascertainment and misclassification bias showed low risk (figure 2). The five papers included for comparison of complication rates between pregnant women exposed to MVC and those who were not exposed (assessed using the Newcastle-Ottawa Scale) showed generally high quality, with four papers scoring 9/9 (6, $26,28,29)$. The remaining paper scored $8 / 9$, losing 1 point for the comparability as it did not control for any secondary factors. ${ }^{27}$

\section{Incidence of complications among pregnant women involved in MVCs}

The assessment of adverse outcome incidence among women involved in MVC (using population-level data) demonstrated incidence estimations of 276.43 per 1000 for induction of labour (95\% CI 262.54-290.54), 191.90 per 1000 for preterm delivery (95\% CI 45.98-405.74) and 166.65 per 1000 for caesarean section (95\% CI 47.34-339.00). The estimated incidence rates for other complications included 42.33 per 1000 for PROM, 17.08 per 1000 requiring admission to hospital, 16.14 per 1000 for placental abruption and 15.19 per 1000 for neonatal respiratory distress. A pooled incidence of maternal death was 3.60 per 1000 women (95\% CI $0.25-10.42,3$ studies, 12000 women, $\mathrm{Tau}=1.77)$. The pooled incidence of perinatal death (fetal death or stillbirth) per 1000 women was 6.60 , (95\% CI 3.81-10.12; 8 studies, 47992 women; $\mathrm{I}^{2}=92.6 \%$ ) (table 2). The representation of the maternal and offspring outcomes according to trauma severity are in appendices (online supplemental appendices 3 and 4). Using data from single hospital centres, the random pooled estimation for the incidence of admission to hospital was 117.92 per 1000 women (95\% CI 109.82$126.40)^{1737}$; for maternal death was 135.05 per 1000 women (95\% CI 131.37-138.80) and for fetal death was 5.73 per 1000 women (95\% CI 3.05-9.77) (online supplemental appendices 5 and 6 ). 


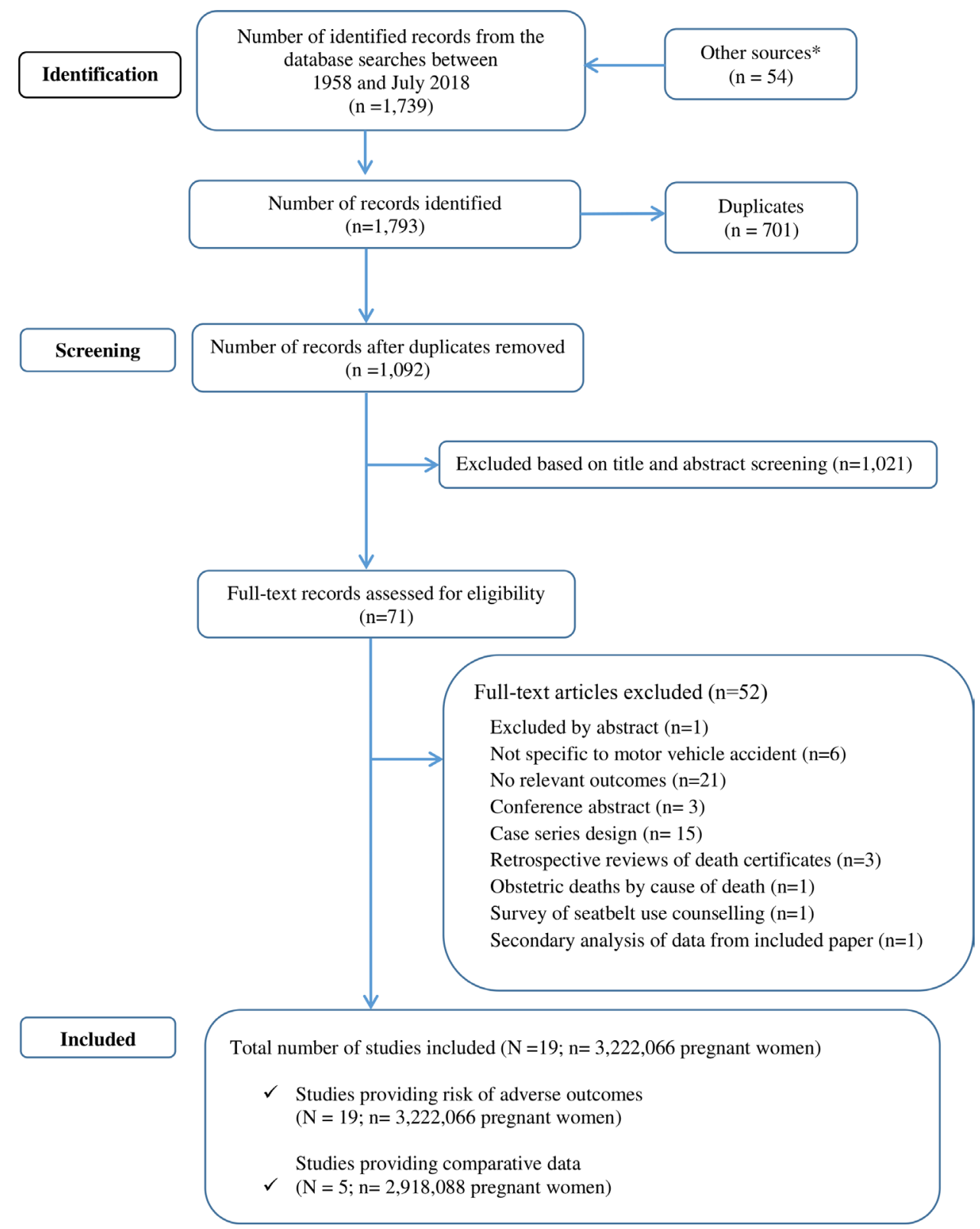

Figure 1 The study selection process in the systematic review of outcomes on pregnant women involved in motor vehicle crashes. ${ }^{\star}$ references of relevant non-systematic reviews and Google Scholar.

\section{Pregnancy complications in women involved versus not involved in MVCs}

We observed a statistically significant link between involvement in MVC and maternal death (OR 202.3, 95\% CI 110.60-370.00; single study) ${ }^{27}$ (data not shown in table or graphic). Figure 3 shows pooled results from population-level data, demonstrating a positive association between MVC and placental abruption (OR 1.43 95\% CI 1.27-1.63). Two studies contributed data used in sensitivity analyses stratifying by seat belt use, where the pooled estimation ${ }^{26}$ of fetal death decreased with seat belt devices, but the association was not statistically significant (OR 0.66 95\% CI 0.36-1.19) (online supplemental figure 1 ). The review manager forest plot displays a positive but not statistically significant association between fetal death and MVC without seat belt use (OR 5.78 95\% CI 0.17 201.12, $\left.\mathrm{Tau}^{2}=6.51\right)$ (online supplemental figure 2).

\section{DISCUSSION}

\section{Statement of principal findings}

This review estimated that for women involved in MVC, maternal death occurrence was 3.6 per 1000 and perinatal death 6.6 per 1000 women. Compared with women not involved in MVC, those involved had an increased odds of placental abruption, antepartum haemorrhage and maternal death. The pooled incidence of complications per 1000 women involved in MVC was, from the higher incidence to the lower, induction of labour, 


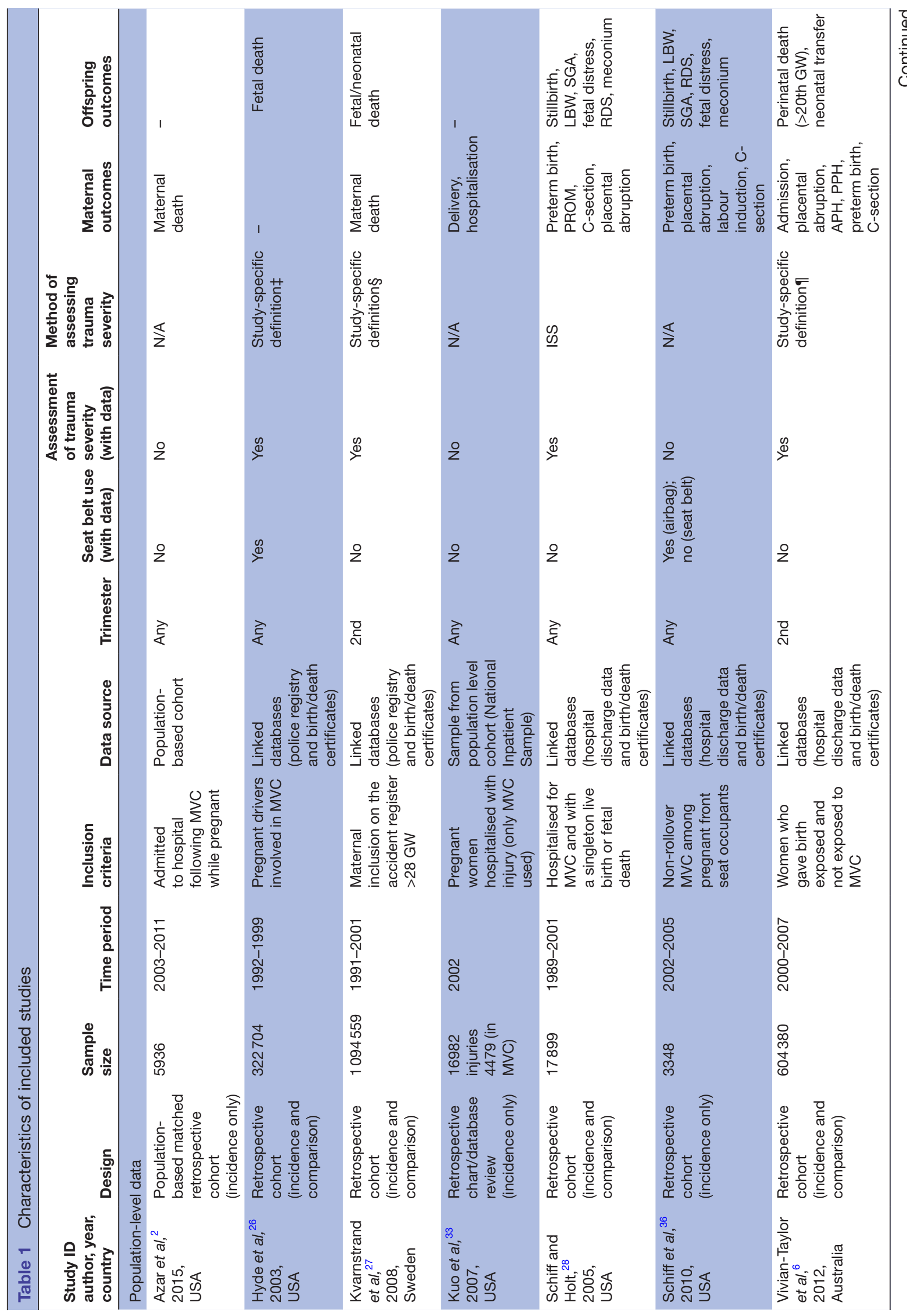




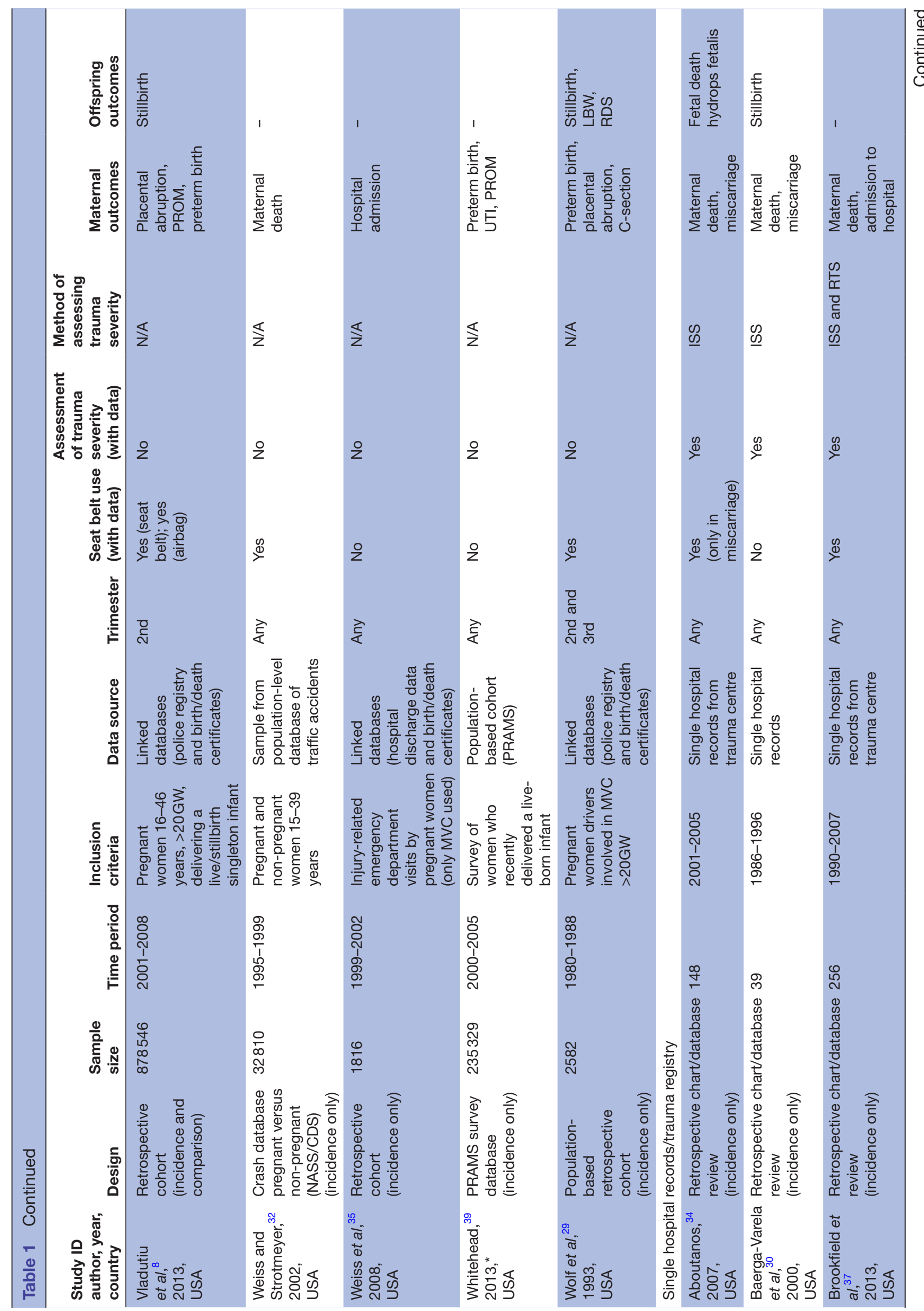



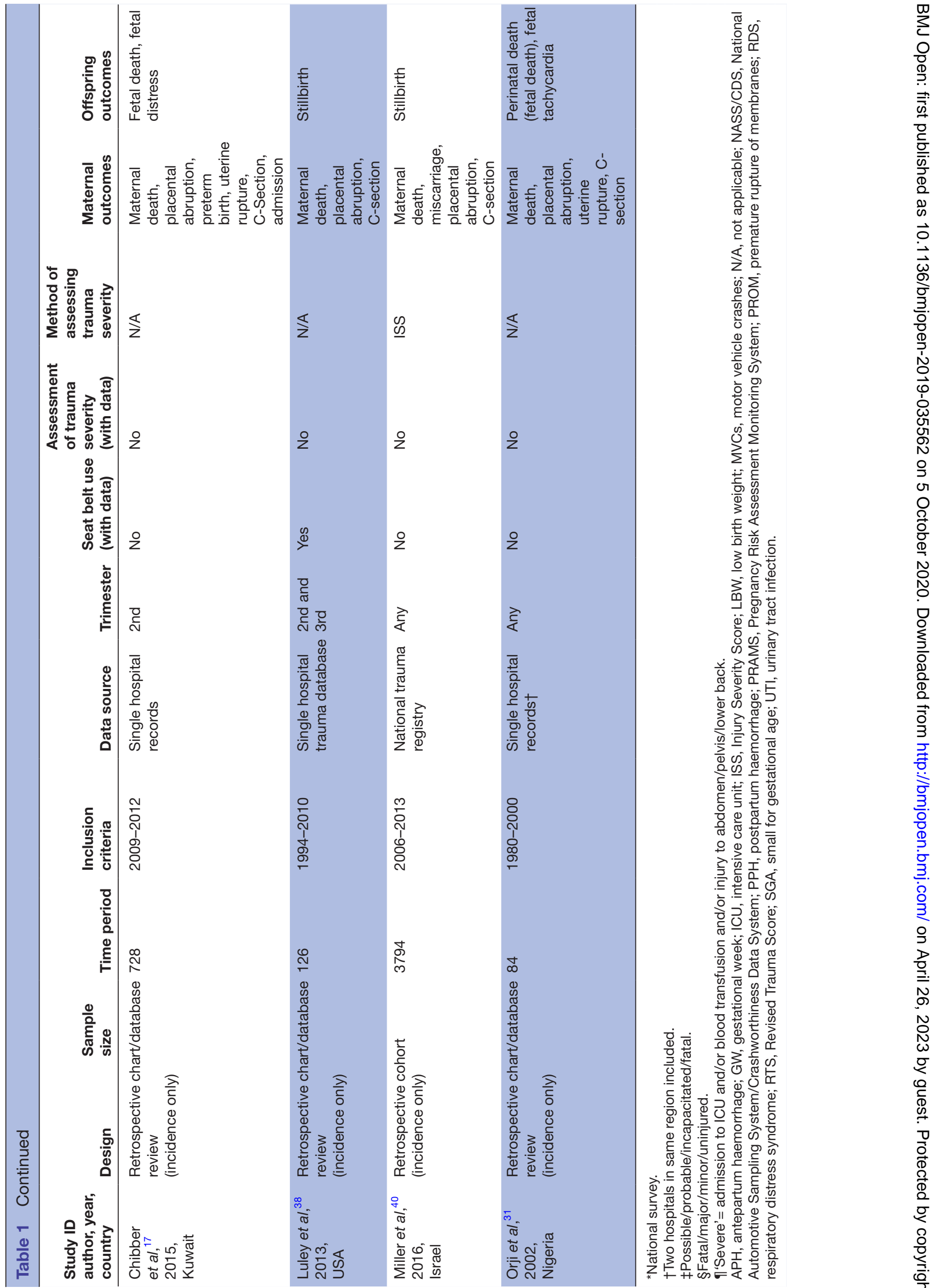

옹

or

음

กิ

뭉

을

踏

잉ㅎำ

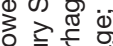

क

क w

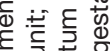

응 웡

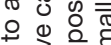

त्क

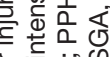

항.

응

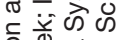

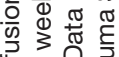

कै वे

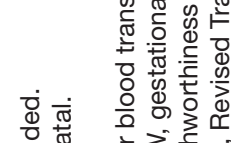

क्ष

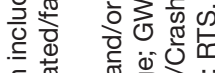

둥

늠 긍

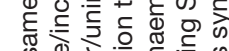

离.

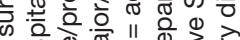

कि

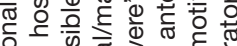

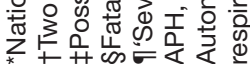




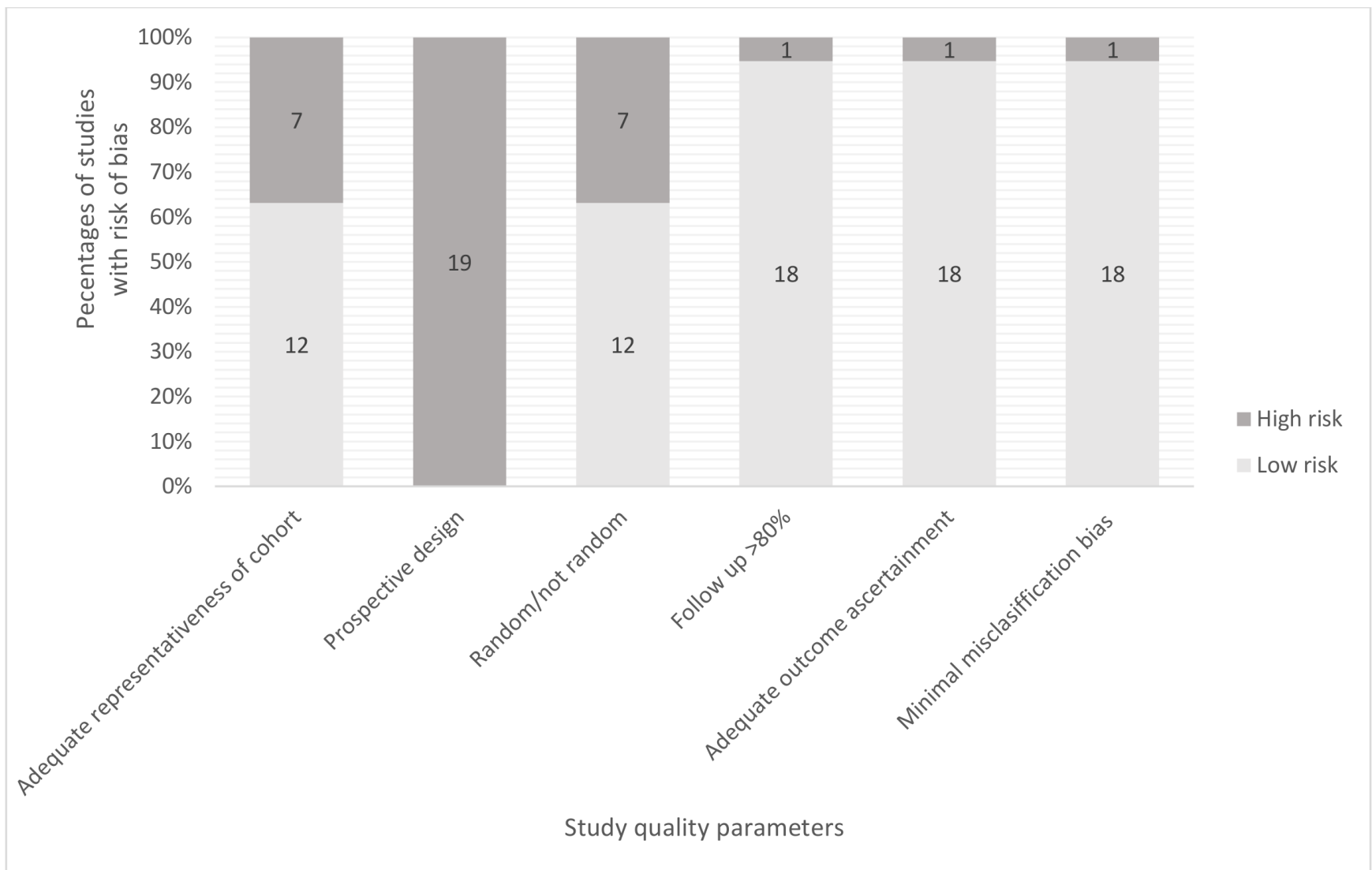

Figure 2 The quality assessment of the included studies.

preterm delivery, caesarean section, PROM and placental abruption (population level-data).

\section{Strengths and weaknesses of this study}

This is the second systematic review, after the one of Mendez-Figueroa et $a l^{4}$, looking at outcomes following MVC in pregnancy. We conducted our review using a prospectively registered protocol and reported it in accordance with the international standards. ${ }^{41}$ This review, to our best knowledge, is the first one examining the link between involvement in MVC, mortality and adverse outcomes that involves evaluation of study quality assessment; 14 studies looking at outcome incidence related to MVC $^{21729-40}$ and 5 studies comparing outcomes in pregnant women involved in MVC and those who were not. $^{6826-28}$ We used established tools to assess outcome reporting quality for the incidence rates ${ }^{42}$ and comparability. ${ }^{23}$ We included data from population-level and single-centre studies, but the analysis and reporting of the results were independent in order to get precision and validity in the estimations. However, a couple of graphics of the maternal and offspring's outcomes incidences have been included as online supplemental appendices 3 and 4. Between August 2018 and March 2020, there have been no new studies eligible to include in the systematic review.

For the incidence analysis, we evaluated the quality of the 19 studies of this systematic review. The highest risk was in the design. None of the studies had a prospective design. The representativeness of cohort and the random method of sampling were other limitations of the quality of studies, with 7 out of 19 studies having a high risk of bias in these areas. ${ }^{17} 303134373840$ However, the quality assessment of the five papers included for comparison of complication rates between pregnant women involved and not involved in MVC using the Newcastle-Ottawa Scale showed generally high quality, with four papers scoring $9 / 9 .{ }^{62628}$

The weaknesses of this systematic review are as follows. First, outcomes were not reported by trimester, with 13 out of 19 papers focused on MVC at any trimester. Second, outcomes, according to seat belt use, are scarce as only two studies using population-level data looked at safety features as a stratification factor. ${ }^{86}$ Two studies with data sourced from hospital records/single-site trauma registries $^{37} 38$ and three studies using population-level databases $^{826} 29$ reported some outcomes regarding seat belt use. Third, we found a limited number of relevant studies comparing outcomes between women involved and not involved in MVC. The majority of the studies were carried out in the USA ${ }^{8628}$ with most recent one published in $2013 .{ }^{8}$ Fourth, the included studies differed in study design with seven of them using hospital records/singlesite trauma registry ${ }^{17} 303134373840$ and twelve population databases. ${ }^{2} 8826-293233353639$ Despite analysing the data within the respective study designs and incorporation of anticipated variation into the statistical model (random-effects) ${ }^{43}$ we encountered substantial statistical 
Table 2 Incidence of adverse outcomes per 1000 women involved in motor vehicle crashes

\begin{tabular}{|c|c|c|c|c|}
\hline Outcome and study & Number of studies & Number of women & $\begin{array}{l}\text { Incidence estimate } \\
\text { per } 1000 \text { women }\end{array}$ & $95 \% \mathrm{Cl}$ \\
\hline \multicolumn{5}{|l|}{ Maternal } \\
\hline Maternal death & 3 & 12000 & 3.60 & $0.25-10.42$ \\
\hline Azar et al, ${ }^{2} 2005$ & & & 6.57 & $4.68-8.97$ \\
\hline Kvarnstrand et al, ${ }^{27} 2008$ & & & 6.61 & $3.70-10.88$ \\
\hline Miller et al,$^{40} 2016$ & & & 0.26 & $0.01-1.47$ \\
\hline Admission to hospital & 2 & 3838 & 17.08 & $13.20-21.46$ \\
\hline Vivian-Taylor et al, ${ }^{6} 2012$ & & & 8.90 & $5.28-14.03$ \\
\hline Weiss et al, ${ }^{35} 2008$ & & & 29.19 & $21.94-38.0$ \\
\hline Placenta abruption & 6 & 36737 & 16.14 & $7.04-28.78$ \\
\hline Wolf et al, ${ }^{29} 1993$ & & & 8.10 & $5.02-12.36$ \\
\hline Miller et al, ${ }^{40} 2016$ & & & 1.05 & $0.29-2.70$ \\
\hline Schiff and Holt, ${ }^{28} 2005$ & & & 113.40 & $88.80-142.01$ \\
\hline Schiff et al, ${ }^{36} 2010$ & & & 12.25 & $8.80-16.58$ \\
\hline Vivian-Taylor et al, ${ }^{6} 2012$ & & & 16.32 & $11.26-22.84$ \\
\hline Vladutiu et $a l,{ }^{8} 2013$ & & & 7.17 & $6.15-8.31$ \\
\hline Preterm delivery & 5 & 265680 & 191.90 & $45.98-405.74$ \\
\hline Schiff and Holt, ${ }^{28} 2005$ & & & 316.15 & $278.53-355.65$ \\
\hline Schiff et al, ${ }^{36} 2010$ & & & 97.37 & 87.53-107.92 \\
\hline Vivian-Taylor et al, ${ }^{6} 2012$ & & & 83.09 & $71.42-95.98$ \\
\hline Vladutiu et $a l,{ }^{8} 2013$ & & & 110.33 & $106.43-114.33$ \\
\hline Whitehead, ${ }^{39} 2013$ & & & 437.00 & $435.00-439.01$ \\
\hline PROM & 3 & 260310 & 42.33 & $5.87-109.24$ \\
\hline Schiff and Holt,, 2005 & & & 22.34 & $11.95-37.89$ \\
\hline Vladutiu et al, ${ }^{8} 2013$ & & & 23.53 & $21.66-25.51$ \\
\hline Whitehead, ${ }^{39} 2013$ & & & 96.00 & $94.81-97.20$ \\
\hline Labour induction & 2 & 3930 & 276.43 & 262.54290 .54 \\
\hline Schiff and Holt,, 2005 & & & 223.37 & $190.15-259.42$ \\
\hline Schiff et al, ${ }^{36} 2010$ & & & 286.14 & $270.87-301.78$ \\
\hline Caesarean section & 5 & 12338 & 166.65 & $47.34-339.00$ \\
\hline Miller et al,${ }^{40} 2016$ & & & 6.06 & $3.85-9.08$ \\
\hline Schiff and Holt, ${ }^{28} 2005$ & & & 254.30 & 219.38-291.73 \\
\hline Schiff et al, ${ }^{36} 2010$ & & & 259.26 & $244.48-274.46$ \\
\hline Vivian-Taylor et al, ${ }^{6} 2012$ & & & 260.14 & $241.13-279.85$ \\
\hline Wolf et al, ${ }^{29} 1993$ & & & 171.68 & $157.35-186.76$ \\
\hline \multicolumn{5}{|l|}{ Offspring } \\
\hline Perinatal death & 8 & 47992 & 6.60 & $3.81-10.12$ \\
\hline Kvarnstrand et al, ${ }^{27} 2008$ & Fetal/neonatal & & 17.62 & $12.62-23.92$ \\
\hline Hyde et al, ${ }^{26} 2003$ & Fetal & & 5.01 & $3.66-6.70$ \\
\hline Miller et al,$^{40} 2016$ & Stillbirth & & 0.79 & $0.16-2.31$ \\
\hline Schiff and Holt, ${ }^{28} 2005$ & Fetal & & 12.03 & $4.85-24.62$ \\
\hline Vivian-Taylor et al, ${ }^{6} 2012$ & Stillbirth & & 16.82 & $11.67-23.42$ \\
\hline Vladutiu et $a l,{ }^{8} 2013$ & Stillbirth & & 5.25 & $4.38-6.23$ \\
\hline Schiff et al, ${ }^{36} 2010$ & Fetal & & 4.18 & $2.29-7.01$ \\
\hline Wolf et al, ${ }^{29} 1993$ & Fetal & & 3.47 & $1.59-6.58$ \\
\hline
\end{tabular}


Table 2 Continued

\begin{tabular}{|c|c|c|c|c|}
\hline Outcome and study & Number of studies & Number of women & $\begin{array}{l}\text { Incidence estimate } \\
\text { per } 1000 \text { women }\end{array}$ & $95 \% \mathrm{Cl}$ \\
\hline Fetal distress & 2 & 3930 & 60.09 & $52.85-67.77$ \\
\hline Schiff et al, ${ }^{36} 2010$ & & & 50.48 & $43.31-58.44$ \\
\hline Meconium at delivery & 2 & 3930 & 52.61 & $45.82-59.85$ \\
\hline RDS & 3 & 6522 & 15.19 & $5.83-28.68$ \\
\hline Schiff and Holt, ${ }^{28} 2005$ & & & 32.65 & $19.77-50.51$ \\
\hline Schiff et al, ${ }^{36} 2010$ & & & 14.64 & $10.85-19.30$ \\
\hline Wolf et al, ${ }^{29} 1993$ & & & 6.17 & $3.53-10.00$ \\
\hline
\end{tabular}

Data source: population database

PROM, premature rupture of membranes; RDS, respiratory distress syndrome.

heterogeneity in the pooled estimates that could not be formally explored due to a limited number of studies and poor reporting of important factors such as trauma severity. As a fifth point, these data apply to developed countries-only one of the papers included data from an underdeveloped country, perhaps influencing the outcomes that might otherwise be seen in the developed world. Finally, in only eight studies did authors assess severity of MVC injuries, with only five of these using a validated tool. ${ }^{2830} 343740$ This was a challenge when aiming to analyse results according to the severity of the crash.

\section{Meaning of the study}

The strongest association was found between placental abruption $^{6828}$ and MVC. Maternal death was associated with involvement in MVC but this finding needs to be treated with caution as the data come from a single study. ${ }^{27}$ The outcomes in descending order of incidence estimate per 1000 (population-level data) were the induction of labour, preterm delivery, caesarean section, PROM and admission to hospital, placental abruption and maternal death. In the analyses stratified by use of

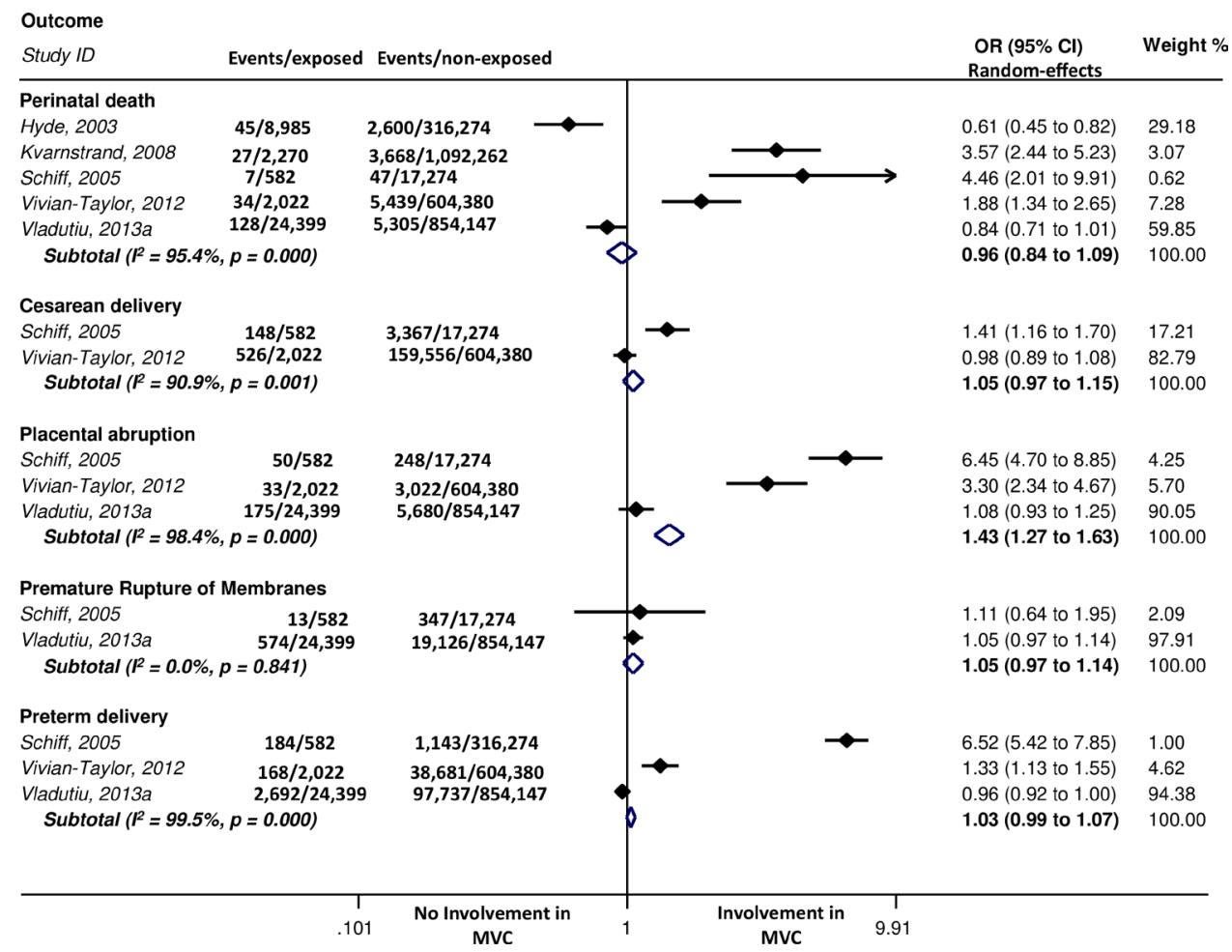

Figure 3 Comparison of outcomes between women involved and not involved in motor vehicle crashes (MVCs). 
seat belts, we observed an association of fetal death with lack of seat belt use by pregnant women involved in an MVC. However, this finding was not statistically significant and informed by a limited number of studies. Previous studies have shown that pregnant women wearing seat belts during the MVC did not experience a significantly higher risk of adverse fetal outcomes than women who were not involved in MVC. ${ }^{26}$ Furthermore, airbags seem to be contributing to the protection of both pregnant drivers and their fetuses. ${ }^{44}$

The results of this systematic review provide evidence informing primary prevention measures, recommendations and educational interventions for pregnant women in the context of MVC that should be incorporated into the primary care guidelines.

\section{Unanswered questions and future research}

The effects of MVC in pregnant women is a specific field that requires further research and an improved methodological approach to determine the risks of adverse maternal and fetal outcomes.

Additional variables such as trauma severity, the position of the women in the car, use of seat belts, deployment or non-deployment of an airbag, severity of the crash and gestational week of pregnancy should be recorded in relation to MVC exposure in order to allow more precision when analysing outcomes. A greater number of well-designed studies in a variety of global settings would strengthen current evidence-base.

\section{CONCLUSIONS}

Pregnant women involved in MVC seem to be at increased risk of maternal death and complications, especially placental abruption, than those not involved in MVC. The risk of complications such as preterm delivery, PROM and caesarean section were also increased. However, these findings need to be treated with caution due to the small number of studies included in the review and considerable differences between studies. Road traffic authorities should be conscious and strict in targeting preventive measures aimed at pregnant users of motor vehicles due to risk associated with potential involvement in MVC.

\section{Author affiliations \\ ${ }^{1}$ Preventive Medicine and Public Health, University of Granada Faculty of Medicine, Granada, Andalucía, Spain \\ ${ }^{2}$ CIBER de Epidemiología y Salud Pública (CIBERESP), Granada, Spain \\ ${ }^{3}$ Instituto de Investigación Biosanitaria, ibs.GRANADA, Granada, Spain \\ ${ }^{4}$ Centre for Trauma Sciences, Queen Mary University of London, London, UK \\ ${ }^{5}$ Women's Health Research Unit, Barts and the London School of Medicine and Dentistry, London, UK \\ ${ }^{6}$ Meta-analysis Group, MRC Clinical Trials Unit, University College London, London, UK}

Contributors PM conducted literature searches and screened publications jointly with JR. CA-P and JR extracted the data. CA-P and ER drafted the manuscript and conducted the statistical analyses. KSK and ST designed the study review. CA-P is the guarantor. VM-R, KB, ABC, ST and KSK gave critical revision of the manuscript. All authors had full access to the data and take responsibility for the data analyses.
Funding The authors have not declared a specific grant for this research from any funding agency in the public, commercial or not-for-profit sectors.

Competing interests None declared.

Patient consent for publication Not required.

Provenance and peer review Not commissioned; externally peer reviewed.

Data availability statement All data relevant to the study are included in the article or uploaded as supplemental information.

Open access This is an open access article distributed in accordance with the Creative Commons Attribution Non Commercial (CC BY-NC 4.0) license, which permits others to distribute, remix, adapt, build upon this work non-commercially, and license their derivative works on different terms, provided the original work is properly cited, appropriate credit is given, any changes made indicated, and the use is non-commercial. See: http://creativecommons.org/licenses/by-nc/4.0/.

ORCID iD

Carmen Amezcua-Prieto http://orcid.org/0000-0002-0957-4057

\section{REFERENCES}

1 Sivak M. Female drivers in the United States, 1963-2010: from a minority to a majority? Traffic Inj Prev 2013;14:259-60.

2 Azar T, Longo C, Oddy L, et al. Motor vehicle collision-related accidents in pregnancy. J Obstet Gynaecol Res 2015;41:1370-6.

3 Weiss HB, Songer TJ, Fabio A. Fetal deaths related to maternal injury. JAMA 2001;286:1863-8.

4 Mendez-Figueroa H, Dahlke JD, Vrees RA, et al. Trauma in pregnancy: an updated systematic review. Am J Obstet Gynecol 2013;209:1-10.

5 Redelmeier DA, May SC, Thiruchelvam D, et al. Pregnancy and the risk of a traffic crash. CMAJ 2014;186:742-50.

6 Vivian-Taylor J, Roberts CL, Chen JS, et al. Motor vehicle accidents during pregnancy: a population-based study. BJOG 2012;119:499-503.

7 Battaloglu E, McDonnell D, Chu J, et al. Epidemiology and outcomes of pregnancy and obstetric complications in trauma in the United Kingdom. Injury 2016;47:184-7.

8 Vladutiu CJ, Marshall SW, Poole C, et al. Adverse pregnancy outcomes following motor vehicle crashes. Am J Prev Med 2013;45:629-36.

9 Manoogian S. Comparison of pregnant and non-pregnant occupant crash and injury characteristics based on national crash data. Accid Anal Prev 2015;74:69-76.

10 Service NH. Car travel in pregnancy. Available: https://www.nhs. uk/conditions/pregnancy-and-baby/travel-pregnant/ - car-travel-inpregnancy

11 Trust NC. Safety guidelines on travelling by car during pregnancy UK. Available: https://www.nct.org.uk

12 Gynecologist ACoOa. Car safetry for pregnant women, babies and children, 2016

13 Deshpande NA, Kucirka LM, Smith RN, et al. Pregnant trauma victims experience nearly 2 -fold higher mortality compared to their nonpregnant counterparts. Am J Obstet Gynecol 2017;217:590. e1-590.e9.

14 Schuster M, Becker N, Young A, et al. Trauma in pregnancy: a review of the Pennsylvania trauma systems Foundation database. Trauma 2018;20:30-7.

15 Gibbins KJ, Silver RM. 981: Trauma/motor vehicle crashes and stillbirth. Am J Obstet Gynecol 2017;216:S552-3.

16 Lien C, Ali A, Culhane J. Blunt abdominal trauma with uterine rupture and fetal demise. Trauma 2017;19:219-21.

17 Chibber R, Al-Harmi J, Fouda M, et al. Motor-Vehicle injury in pregnancy and subsequent feto-maternal outcomes: of Grave concern. J Matern Fetal Neonatal Med 2015;28:399-402.

18 Brown S, Mozurkewich E. Trauma during pregnancy. Obstet Gynecol Clin North Am 2013;40:47-57.

19 Einav S, Sela HY, Weiniger CF. Management and outcomes of trauma during pregnancy. Anesthesiol Clin 2013;31:141-56.

20 Mirza FG, Devine PC, Gaddipati S. Trauma in pregnancy: a systematic approach. Am J Perinatol 2010;27:579-86.

21 Smith KA, Bryce S. Trauma in the pregnant patient: an evidencebased approach to management. Emerg Med Pract 2013;15:1-18.

22 Moher D, Liberati A, Tetzlaff J, et al. Preferred reporting items for systematic reviews and meta-analyses: the PRISMA statement. BMJ 2009;339:b2535. 
23 Lo CK-L, Mertz D, Loeb M. Newcastle-Ottawa scale: comparing reviewers' to authors' assessments. BMC Med Res Methodol 2014;14:45.

24 Cheong-See F, Schuit E, Arroyo-Manzano D, et al. Prospective risk of stillbirth and neonatal complications in twin pregnancies: systematic review and meta-analysis. BMJ 2016;354:i4353.

25 Deng Q, Tang B, Xue C, et al. Comparison of the ability to predict mortality between the injury severity score and the new injury severity score: a meta-analysis. Int J Environ Res Public Health 2016;13. doi:10.3390/ijerph13080825.

26 Hyde LK, Cook LJ, Olson LM, et al. Effect of motor vehicle crashes on adverse fetal outcomes. Obstet Gynecol 2003;102:279-86.

27 Kvarnstrand L, Milsom I, Lekander T, et al. Maternal fatalities, fetal and neonatal deaths related to motor vehicle crashes during pregnancy: a national population-based study. Acta Obstet Gynecol Scand 2008;87:946-52.

28 Schiff MA, Holt VL. Pregnancy outcomes following hospitalization for motor vehicle crashes in Washington State from 1989 to 2001. [Erratum appears in Am J Epidemiol. 2005 Jul 15;162(2):197]. American Journal of Epidemiology 2005;161:503-10.

29 Wolf ME, Alexander BH, Rivara FP, et al. A retrospective cohort study of seatbelt use and pregnancy outcome after a motor vehicle crash. $J$ Trauma 1993;34:116-9.

30 Baerga-Varela Y, Zietlow SP, Bannon MP, et al. Trauma in pregnancy. Mayo Clin Proc 2000;75:1243-8.

31 Orji EO, Fadiora SO, Ogunlola IO, et al. Road traffic accidents in pregnancy in Southwest Nigeria: a 21-year review. J Obstet Gynaecol 2002;22:516-8.

32 Weiss HB, Strotmeyer S. Characteristics of pregnant women in motor vehicle crashes. Inj Prev 2002;8:207-10.

33 Kuo C, Jamieson DJ, McPheeters ML, et al. Injury hospitalizations of pregnant women in the United States, 2002. Am J Obstet Gynecol 2007;196:161.e1-161.e6.
34 Aboutanos MB, Aboutanos SZ, Dompkowski D, et al. Significance of motor vehicle crashes and pelvic injury on fetal mortality: a five-year institutional review. J Trauma 2008;65:616-20.

35 Weiss HB, Sauber-Schatz EK, Cook LJ. The epidemiology of pregnancy-associated emergency department injury visits and their impact on birth outcomes. Accid Anal Prev 2008;40:1088-95.

36 Schiff MA, Mack CD, Kaufman RP, et al. The effect of air bags on pregnancy outcomes in Washington state: 2002-2005. Obstet Gynecol 2010;115:85-92.

37 Brookfield KF, Gonzalez-Quintero VH, Davis JS, et al. Maternal death in the emergency department from trauma. Arch Gynecol Obstet 2013;288:507-12.

38 Luley T, Fitzpatrick CB, Grotegut CA, et al. Perinatal implications of motor vehicle accident trauma during pregnancy: identifying populations at risk. Am J Obstet Gynecol 2013;208:466.e1-466. e5.

39 Whitehead NS. Prenatal counseling on seat belt use and crashrelated medical care. Matern Child Health J 2013;17:1527-32.

40 Miller N, Biron-Shental T, Peleg K, et al. Are pregnant women safer in motor vehicle accidents? J Perinat Med 2016;44:329-32.

41 Liberati Aet al. The PRISMA statement for reporting systematic reviews and meta-analyses of studies that evaluate health care interventions: explanation and elaboration. Ann Intern Med 2009;151:W-94.

42 Glasziou P, Irwig L, Bain C, et al. Frequency and rate. In: Systematic reviews in health care: a practical guide. 2nd edn. Cambridge, UK: Cambridge University Press, 2001: 67-73.

43 Colditz GA, Burdick E, Mosteller F. Heterogeneity in meta-analysis of data from epidemiologic studies: a commentary. Am J Epidemiol 1995;142:371-82.

44 Acar BS, Meric M. The effect of placenta location on the safety of pregnant driver and her fetus. International Journal of Crashworthiness 2017;22:163-8. 